\title{
Eletrificação e formação do patrimônio territorial da Light na cidade do Rio de Janeiro e no Médio Vale do Paraíba
}

L'électrification et la formation du patrimoine territorial de la Light à la ville de Rio de Janeiro et dans la moyenne vallée de la Parahybe

Electrification and formation of Light's territorial patrimony in the city of Rio de Janeiro and in the Middle Valley of Paraiba

Electrificación y formación del patrimonio territorial de la empresa Light en la ciudad de Rio de Janeiro y en el Medio Valle del Paraíba

\section{Floriano José Godinho de Oliveira}

\section{(2) OpenEdition}

\section{Journals}

Edição electrónica

URL: http://journals.openedition.org/espacoeconomia/497

DOI: 10.4000/espacoeconomia.497

ISSN: 2317-7837

\section{Editora}

Núcleo de Pesquisa Espaço \& Economia

Refêrencia eletrónica

Floriano José Godinho de Oliveira, « Eletrificação e formação do patrimônio territorial da Light na cidade do Rio de Janeiro e no Médio Vale do Paraíba », Espaço e Economia [Online], 3 | 2013, posto online no dia 19 dezembro 2013, consultado o 30 abril 2019. URL : http://journals.openedition.org/ espacoeconomia/497 ; DOI : 10.4000/espacoeconomia.497

Este documento foi criado de forma automática no dia 30 Abril 2019.

(c) NUPEE 


\section{Eletrificação e formação do patrimônio territorial da Light na cidade do Rio de Janeiro e no Médio Vale do Paraíba}

L'électrification et la formation du patrimoine territorial de la Light à la ville de Rio de Janeiro et dans la moyenne vallée de la Parahybe

Electrification and formation of Light's territorial patrimony in the city of Rio de Janeiro and in the Middle Valley of Paraiba

Electrificación y formación del patrimonio territorial de la empresa Light en la ciudad de Rio de Janeiro y en el Medio Valle del Paraíba

Floriano José Godinho de Oliveira

\section{Introdução}

1 A relação entre a formação de rede técnica de eletrificação e implantação dos transportes urbanos e do patrimônio territorial, urbano e rural, da Light no Rio de Janeiro, demonstra as articulações que a Companhia realizou junto aos governos estaduais e da União ao longo de toda a primeira metade do século XX. O presente trabalho procura evidenciar as estratégias adotadas pela Companhia no delineamento do monopólio dos serviços e na produção do seu latifúndio.

Quando chegou ao antigo Distrito Federal, a cidade do Rio de Janeiro, a Light and Power desenvolveu uma estratégia, já aplicada na cidade de São Paulo, de associar a produção de energia elétrica por meio de usinas hidrelétricas ao uso de energia no sistema de bondes urbano. Tratou-se de uma tática de associar a produção e o consumo durante os primeiros anos de implantação do sistema elétrico, garantindo a demanda de parte significativa da oferta, enquanto se disseminava a cultura da energia elétrica nos demais setores produtivos e de serviços. 
3 Adquirido o monopólio tanto da produção e distribuição de energia na cidade do Rio de Janeiro quanto da oferta de transportes sobre trilhos e de ônibus elétricos no perímetro urbano, a Companhia articulou esse mercado com as empresas e agentes imobiliários, produzindo valorização das terras urbanas e estabelecendo formas de renda diferencial e de monopólio na produção (Harvey, 1980) e comercialização de novas áreas para a expansão do tecido urbano na cidade do Rio de Janeiro, por meio da criação de novos bairros e empreendimentos.

4 No mesmo período, entre os anos de 1905 e 1962, em face da intensa expansão urbana da cidade e de sua área metropolitana, e da crescente demanda por energia, a empresa implantou sucessivas modernizações dos sistemas produtores de energia e de extensão da rede elétrica, expandindo as atividades de geração de suas usinas hidrelétricas, que facilitaram a ampliação das instalações geradoras e, em consequência, incorporação de terras ao seu patrimônio na região centro-sul do estado, particularmente no Médio Vale do Rio Paraíba fluminense. Trata-se da criação das usinas e estações elevatórias da Ilha dos Pombos, em 1924, Fonte Nova, em 1940, Santa Cecília, Vigário e Nilo Peçanha, em 1952, e Pereira Passos, em 1962.

5 Este trabalho tem como objetivo apresentar alguns aspectos socioespaciais acerca da formação desse patrimônio fundiário e suas implicações no estado, em termos de ocupação de grandes quantidades de terras, para controlar o sistema hídrico, quanto da indução da urbanização da cidade, por meio de ações especulativas e direcionamento dos vetores de crescimento, vinculados à expansão do sistema de transportes na cidade do Rio de Janeiro.

\section{A implantação do sistema elétrico: tecnologia e política em um jogo de cartas marcadas}

6 O desenvolvimento e a difusão das novas tecnologias no campo energético, particularmente o de refino do petróleo, no decorrer da segunda metade do século XIX, culminaram na instituição do que podemos chamar de segunda revolução industrial. Nesse período conjugam-se mais intensamente as estruturas técnicas do primeiro período com os avanços científicos em todos os campos do conhecimento, particularmente os de química, física e eletricidade. Inicia-se aí o que Milton Santos denominaria meio-técnicocientífico (Santos, 1996). Técnica e ciência tornam-se os ingredientes fundamentais para uma nova ordem na reprodução das relações sociais de produção e, em consequência, a instituição de uma nova ordem industrial e urbana.

7 A diminuição da dependência do carvão como matriz energética e a ampliação de fontes como o petróleo possibilitaram um salto tecnológico espetacular. Em primeiro lugar, por meio do aprimoramento dos motores a combustão, então alimentados por óleo combustível, o que permitiu uma intensa mobilidade espacial das estruturas produtivas industriais. O desenvolvimento desses motores, nos primeiros anos do século XX, possibilitou maior mobilidade em curtas distâncias, em fase de uso crescente dos automóveis e dos caminhões. O resultado espacial mais evidente de todas essas transformações foi a expansão da urbanização das cidades industriais em todo o mundo.

8 No Brasil, país que ainda estava em fase inicial de sua industrialização, a ampliação das atividades industriais e, por conseguinte, a intensificação de sua urbanização, ocorre sob a égide desse novo paradigma. Rio de Janeiro e São Paulo, nesse novo contexto, tornam-se 
áreas de grande interesse de investimentos dos novos setores dinâmicos da economia, como o de eletricidade. Por esse motivo, o engenheiro norte-americano Frederick Stark Pearson cria no Brasil suas primeiras empresas de eletricidade, num projeto em que pretende associar a cidade ao negócio de geração de energia, por meio da combinação da eletricidade com os transportes urbanos.

"En aquesta etapa F.S. Pearson deixa de ser exclusivament assessor tècnic ( $\mathrm{i}$ eventual inversor) i fa el salt a promotor d'empreses. Promou empreses elèctriques lligades a la ciutat i a la hidroelectricitat, una nova font energética que li permet fer un salt d'escala en la indústria elèctrica i implantar-se em entorns urbans en ràpid creixement industrial. Combina aquestes elèctriques amb altres serveis urbans altament consumidors de força motriu elèctrica, bàsicament els tramvies, creant grans grups empresarials al voltant de l'electricitat. [como as criadas em São Paulo, 1898, México, 1902, e Rio de Janeiro, 1904]" (Berenger, 2008:16).

Os antecedentes desses empreendimentos no Brasil ocorreram 20 anos antes, quando a energia elétrica se tornou realidade no ano de 1879 , com a inauguração do serviço de iluminação da Estação Ferroviária Central do Brasil, na cidade do Rio de Janeiro e, em 1881, de um trecho da Praça da República, na mesma cidade. Em 1883, entra em operação, na cidade de Diamantina, estado de Minas Gerais, a primeira usina hidrelétrica de pequeno porte do País e, em 1889, tem início a operação da primeira hidrelétrica nacional de porte grande para a época, a Marmelos-Zero, da Companhia Mineira de Eletricidade, pertencente ao industrial Bernardo Mascarenhas (Escelsa, 2010). $O$ uso da energia elétrica nos transportes em nosso país também ocorreu simultaneamente ap seu desenvolvimento na Europa e nos EUA. Em 1892, deu-se a inauguração da primeira linha de bondes (transvias) elétricos de caráter permanente do País, também no Rio de Janeiro.

10 Nesse final do século XIX, o Brasil vivia um intenso processo de modernização tecnológica e de consolidação de suas áreas urbanas, como se pode observar pela evolução do sistema ferroviário, que, no início dos anos 1870, era de $740 \mathrm{~km}$ e atinge a extensão de $9.000 \mathrm{~km}$ no final dos anos 1890. Outro fator importante nesse processo de modernização foi a implantação da rede de telégrafos que, em 1874 foi conectada à Europa por cabos submarinos. Nesse período a rede interna, interligando várias partes do País, alcançava a extensão de $10.000 \mathrm{~km}$ (Andreatta, 2007:230).

11 Em consequência, as demandas crescentes de energia, comunicação, transportes e outros serviços urbanos se consolidam e acabam por atrair investimentos estrangeiros. Para garantir seus investimentos, contudo, as estratégias das empresas que vinham se instalar no Brasil tiravam proveito da fraca base tecnológica e dos conflitos de interesses entre as classes dominantes à época para negociar vantagens e instituir um modo de produção baseado em algum grau de monopolização da produção e oferta dos serviços. Predominou, assim, a instituição de fortes monopólios de geração e distribuição de energia, bem como de intenso controle e oferta de modernização dos sistemas de transportes urbanos e bondes (transvias), o que influiu significativamente na urbanização brasileira.

12 Em 1899, no dia 7 de abril, é fundada em São Paulo a Tramway, Light and Power Company Limited, incorporada a Toronto (Ontário, Canadá), com um capital de 6 milhões de dólares. Esse capital foi conseguido mediante os estudos realizados por Pearson no ano anterior, que mostravam o grande potencial econômico da Cidade de São Paulo, em face de que na cidade "s'hi concentren els principals beneficis del negoci del cafè, hi ha uns potents establiments bancaris $i$ hi ha un desenvolupament industrial latent dificultat per l'alt cost de l'energia degut a la necessària importació del carbó" (Berenger, 2008:17). 
13 En 14 mesos, un temps récord, es va construir una presa i una casa de turbines a Parnaíba que generava $2000 \mathrm{~kW}$ de potència, al riu Teitê, a $33 \mathrm{~km}$ de la ciutat, i una línia de d'alta tensó doble per transmetre l'electricitat. Les obres es van iniciar al 16 de setembre de 1899 sota les ordres de l'enginyer canadenc A.W.K. Billings, que ja es va vincular a les empreses de Pearson treballant anys més tard a Barcelona, i la central va entrar en funcionament per primera vegada al 23 de setembre de 1901. La central aprofitava una caiguda d'aigua de 12 metres alimentada per un embassament de 700 hectàrees mitjançant 3 turbines, i els aparells elèctrics van ser proveïts per la General Electric dels Estats Units (Berenger, 2008:17).

14 A Light, paralelamente às obras de construção da hidrelétrica, investe no sistema de bondes da cidade, utilizando energia gerada em usinas termoelétricas a vapor. Assim, em muito pouco tempo, devido ao aporte de recursos e bons relacionamentos e contatos políticos em São Paulo, a Companhia estabelece uma política de contratos e unificação dos serviços de geração de energia e serviços de transportes urbanos. Com isso, sem muito esforço, já em 1901 a Companhia absorve as demais empresas existentes, como a Companhia de Água e Luz de São Paulo e a Companhia Carris de Ferro de São Paulo, dando início ao forte monopólio de produção e distribuição de energia no Brasil. Concretamente, como afirma Elisabeth Weib, “estas duas áreas deram à empresa canadense uma base suficiente para concorrer com as outras companhias que estivessem no seu caminho, ou absorvê-las".

Em uma década, o crescimento da companhia foi notável. Em 1900, a Light operava uma rede de trilhos eletrificados de $24 \mathrm{~km}$ e 25 bondes elétricos e, em 1912, a rede já totalizava uma extensão de $202 \mathrm{~km}$ e operava um total de 257 veículos elétricos. Tal fato evidencia o potencial de consumo e aumento exponencial da demanda nesse início de século na Cidade de São Paulo. Associado a esse crescimento verifica-se, também, o papel desempenhado pela Companhia no processo de urbanização da cidade. Mesmo sem operar no campo imobiliário, a expansão da rede de bondes em todas as zonas já urbanizadas, bem como nas áreas pouco adensadas nos limites da cidade, fizeram com que a empresa estabelecesse acordos com as empresas que operavam nesse campo. O sucesso nesse empreendimento foi tão grande que o engenheiro Pearson buscou outros mercados, em especial a cidade do México, em 1902, e a cidade do Rio de Janeiro, em 1904, com a mesma intenção de dominar a geração de energia e a gestão dos transvias. È a consolidação do projeto de associar a produção da cidade aos negócios de energia e transvias.

Em julho de 1904 é criada a Rio de Janeiro Tramway, Light and Power Company Limited. A companhia inicia suas atividades com um aporte de 4 milhões de dólares, obtidos pela associação da empresa criada por Pearson, nos EUA, com os grupos financeiros de Toronto (Berenger, 2008:44). Diferentemente de São Paulo, que em 1900 tinha uma população de cerca de 240 mil habitantes e iniciava seu processo de industrialização, o Rio de Janeiro já passava dos 800 mil em 1904 e, pelo fato de ser a Capital da República e a cidade mais industrializada do País, dispunha de uma trama urbana de maior complexidade e de grande número de serviços e infraestrutura já instalados. Essas dificuldades foram bem sintetizadas por Weid, ao mostrar as redes de serviços e concessões já em funcionamento:

“A capital da República era um mercado tentador para os projetos dos dois empresários mas, além das dificuldades político-burocráticas, havia interesses estabelecidos em quase todas as áreas que lhes convinham. A iluminação da capital era concessão da companhia belga Société Anonyme du Gaz, tanto por meio do gás quanto da eletricidade; os transportes coletivos sobre trilhos dependiam de 
concessões pertencentes a diversas empresas que tinham privilégios de área dividindo a cidade: a Companhia Jardim Botânico dominava a zona sul e a orla marítima, a Companhia de São Cristóvão servia a Cidade Nova e a zona portuária, a Companhia de Carris Urbanos controlava o centro da cidade e a Companhia Vila Isabel, pertencente ao grupo alemão Siemens Halske Aktien Gesellschaft, tinha o controle da área que se estendia para a Tijuca e zona norte. Além de outras pequenas empresas com circuitos reduzidos ou distantes. 0 grupo alemão tinha também o controle das comunicações telefônicas, com a empresa Brasilianische Elektricitäts Gesellschaft, cuja compra era incluída como condição para a aquisição da Companhia Vila Isabel. A concessão para a produção de energia hidroelétrica estava em questão, pois seu titular, William Reid, tinha desistido de desenvolvê-la e a vendera ao Banco Nacional, que incorporara para isso a Companhia Nacional de Eletricidade. Havia um grande número de empresários interessados em adquiri-la, apesar de estar sua aplicação limitada à distribuição de força motriz, uma vez que a iluminação era privilégio da empresa belga" (WEID, 1994:4).

Todavia, com a demanda crescente de energia o engenheiro americano Pearson e o canadense Mackenzie resolveram enfrentar os desafios, em face das perspectivas favoráveis que despontavam na cidade. A primeira dificuldade a ser superada foi obter a concessão de exploração do Rio Laje, para a construção de sua hidrelétrica, já concedida à William Reid \& Cia., bem como adquirir as ações de outras empresas, inclusive a belga Société Anonyme du Gaz. Isso foi conquistado já no ano de 1905, devido ao bom relacionamento político e à rápida associação feita com a direção do Clube de Engenharia do Rio de Janeiro.

Em 1905, iniciava-se a construção da Usina de Fontes para produzir energia elétrica gerada por força hidráulica. Para viabilizar o funcionamento da usina, iniciou-se também a construção da barragem e do reservatório de água em uma área situada na porção sul do planalto da Serra do Mar, localizada a 64 quilômetros do Rio de Janeiro, nos municípios de Piraí, São João Marcos e Mangaratiba. A construção da usina transcorreu em meio a uma grave crise financeira interna da empresa, devido à necessidade de realizar simultaneamente vários outros investimentos na cidade, e a um surto de malária, que perdurou durante os três anos de construção da represa na região de Lajes e nas cidades próximas, como Piraí e São João Marcos.

19 Em termos de produção de energia, em 1908, enfim, entra em operação a Hidrelétrica de Fontes (fotos 1 e 2 - prédio menor, à esquerda na foto), situada no município de Piraí, para a qual foi construída a represa de Ribeirão das Lajes (fotos 3 e 4), a maior hidrelétrica do Brasil naquele momento. A capacidade de geração de energia foi aumentada, em 1913, em mais de $60 \%$ com a inauguração do segundo sistema de alimentação da Usina (prédio maior da foto 1 ).

Foto 1 : Usina de fontes 


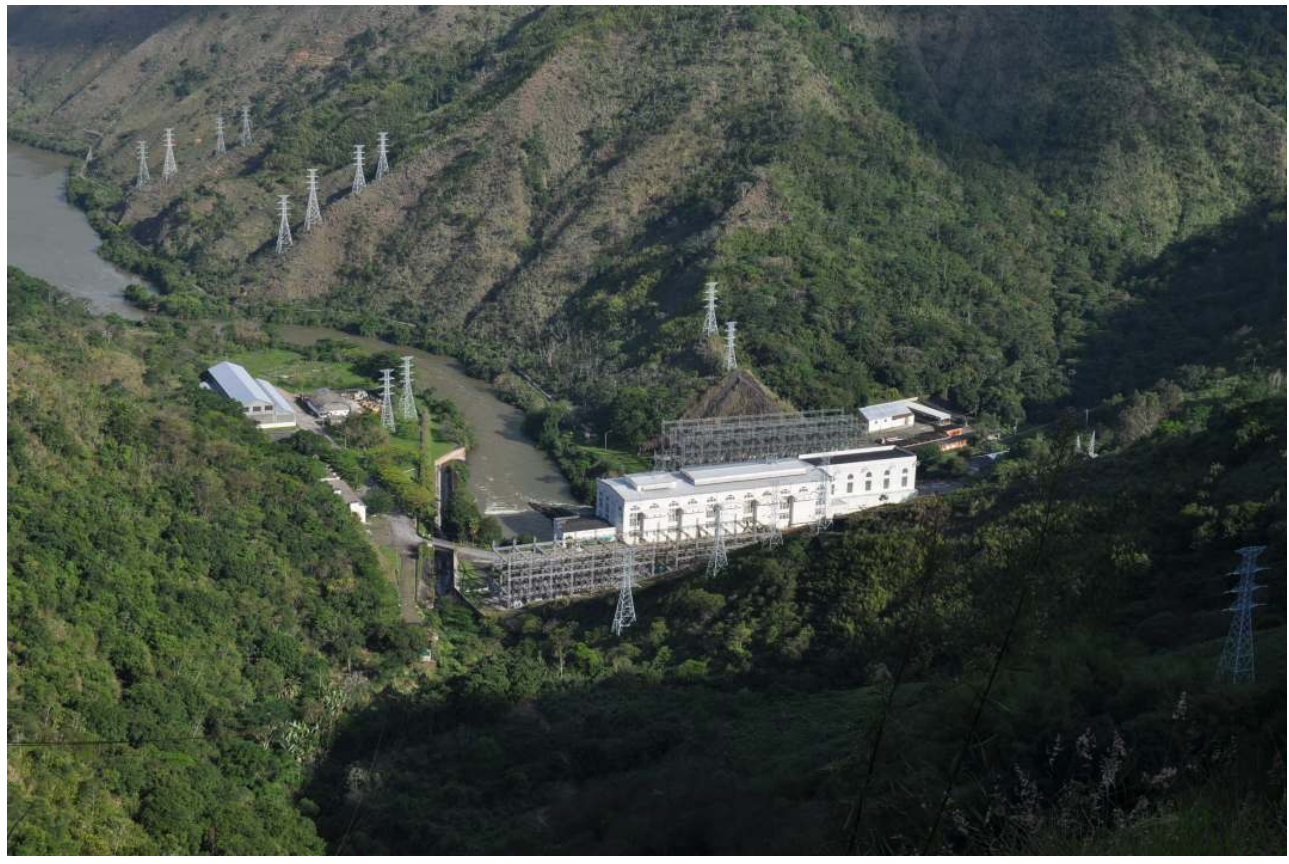

Foto 2 : Usina de Fontes Nova

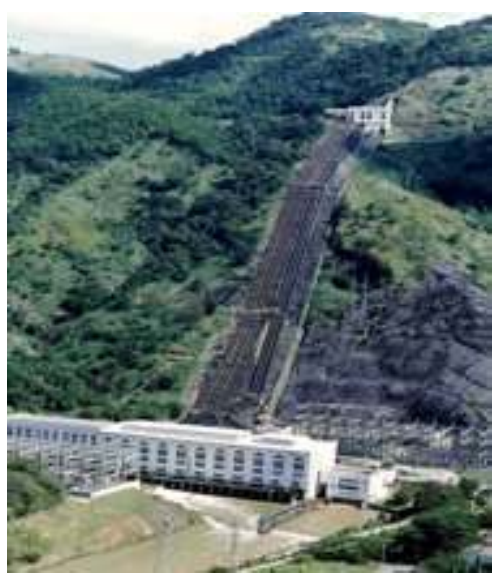

FONTE : LIgHT 
Fotos 3: Represa de Ribeirão das Lajes, Piraí.

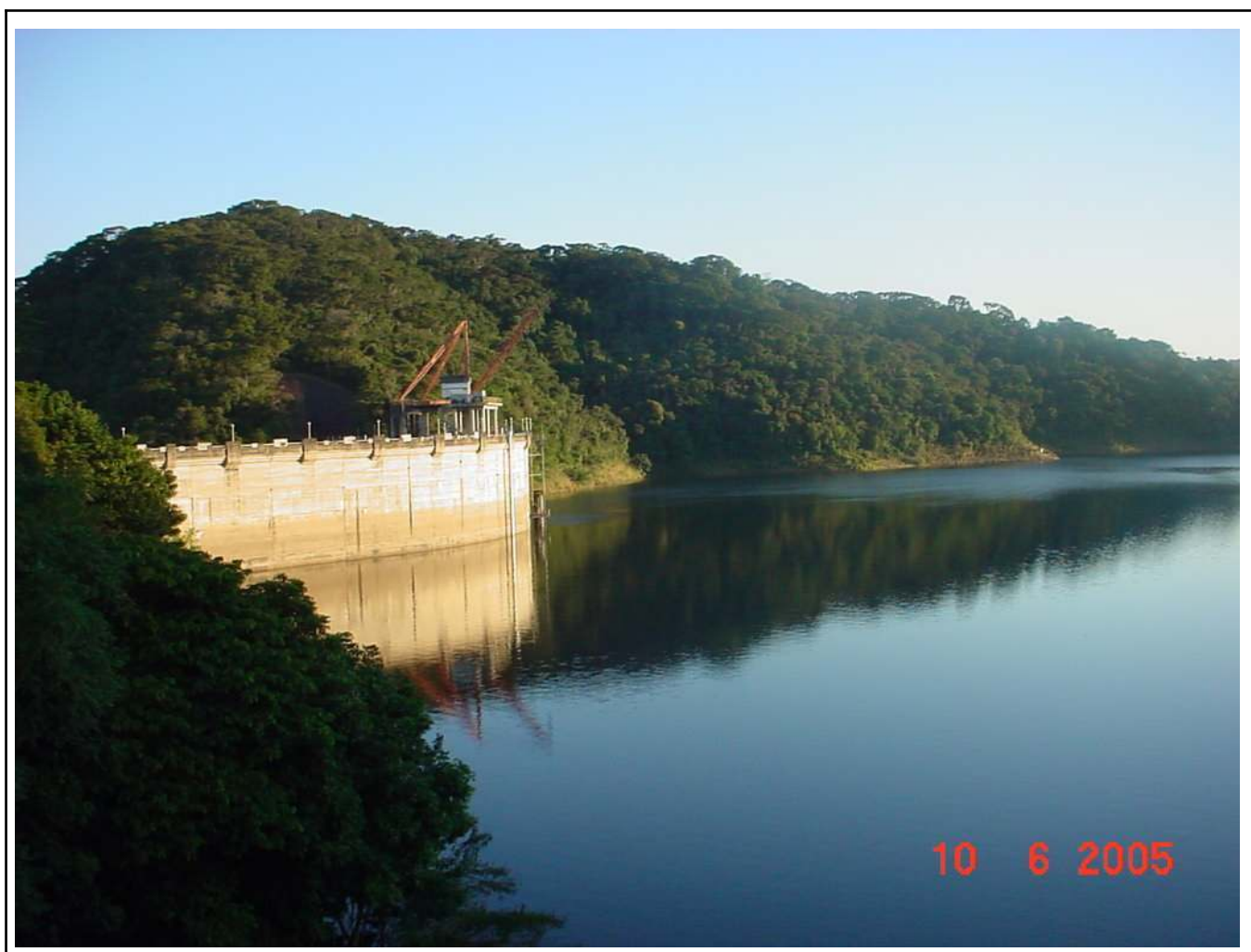

FONTE: FLORIANO J. G. DE OLIVEIRA, 2005. 


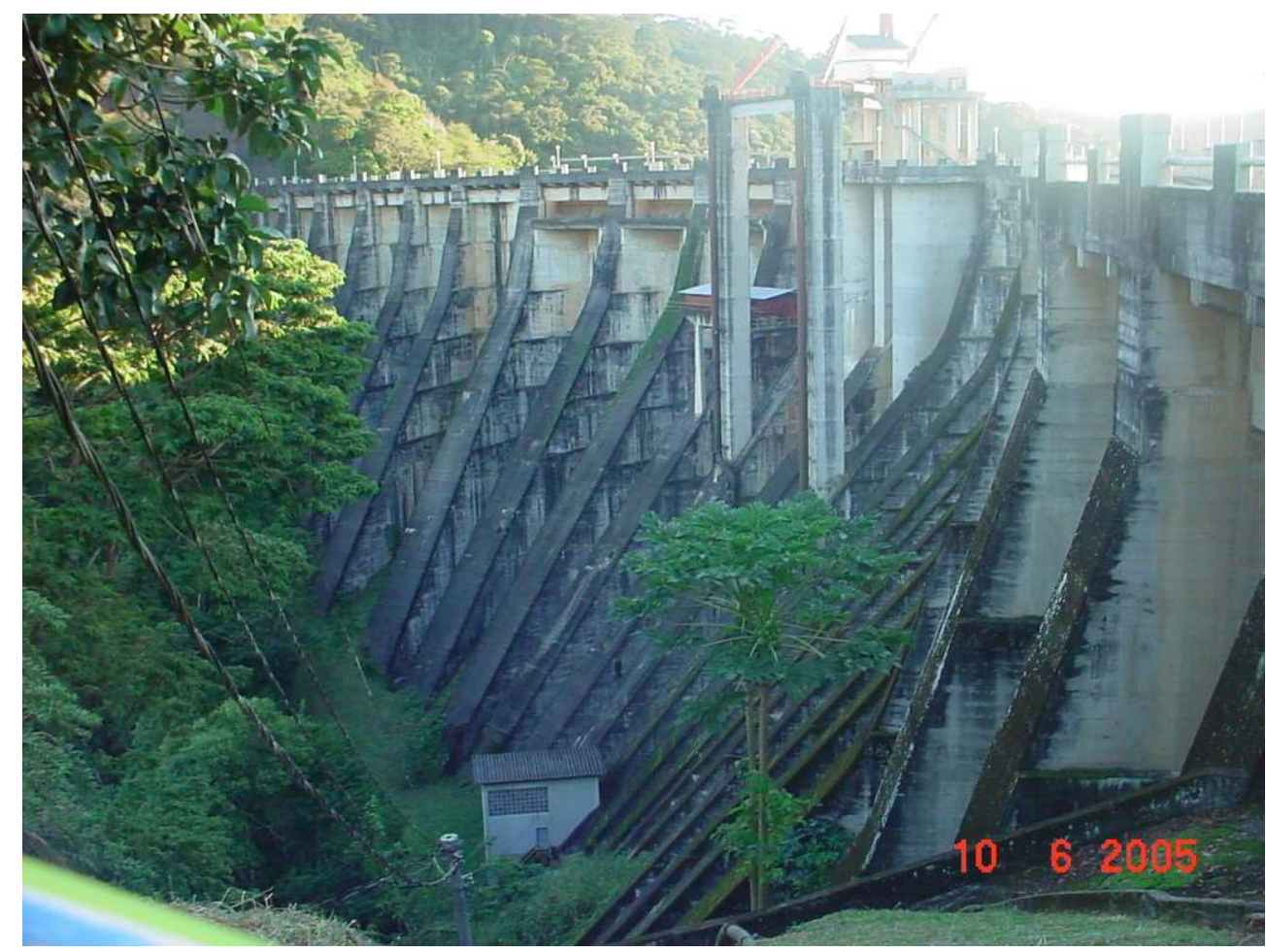

FONTE : FLORIANO J.G. DE OLIVEIRA, 2005.

No transcurso desses anos, enquanto construía as represas, a Rio Light buscou estabelecer a dominação monopolística da produção e distribuição de energia no Distrito Federal e nos demais municípios na parte sul do Estado do Rio de Janeiro. Mas, para conseguir esse objetivo, com vistas ao monopólio de produção e distribuição de energia e serviços de transvias, a Rio Light acaba se convertendo em empresa com atuação em outras áreas, como as de serviços de iluminação pública, telefonia e distribuição de gás, já que, "per a arribar a tenir el monopoli energètic, que finalment aconsegueix, va comprar una sèrie d'empreses i va acabar controlant, també de forma monopolística, els serveis públics de tramvies, de gas, d'enllumenat i de telefonia" (Berenger, 2008:46). Inegavelmente, o maior interesse da Companhia era a produção de energia e transvias, cujo controle absoluto detém durante toda a primeira metade do século XX, e fazer com que "la Light (de hecho el grupo Brazilian Traction Light) se convirtió en um monopolio de los servicios urbanos, que a su vez comenzó a operar en inversiones y emprendimientos inmobiliarios, mediante la Brazilian Securities Company Ltd creada en 1904 (Andreatta, 2007:242).

21 Já em 1905, a Rio Light obtém a concessão de exploração de várias linhas de bondes na cidade, e pouco a pouco vai adquirindo as demais concorrentes, como La Ferro Carril e Hotel Corcovado, as empresas de bonde Companhia de São Cristóvão, Companhia de Carris Urbanos, Companhia Ferro Carril Carioca, Companhia Ferro Carril do Jardim Botânico e a Companhia Ferro-Carril de Vila Isabel (Berenger, 2008:47). Em 1909, já domina monopolisticamente todo esse serviço na cidade, à exceção de uma pequena companhia de bondes na Ilha do Governador.

22 A empresa de Pearson no Rio de Janeiro, portanto, adquire grande influência no processo de expansão da cidade, já que seu crescimento em direção à zona sul e ao maciço da Tijuca 
é sustentado exclusivamente no transporte sobre trilhos. Esse processo foi inaugurado já em 1892, com a eletrificação dos primeiros bondes em direção ao Jardim Botânico e a Copacabana, influindo decisivamente na consolidação desses bairros. 0 mesmo ocorreria no sentido de Tijuca e Vila Isabel, bairros em que se situavam grandes chácaras que, com a chegada dos bondes, foram loteadas.

Com as grandes reformas urbanísticas promovidas pelo prefeito Pereira Passos a partir de 1904 no centro da cidade, a migração para os bairros próximos ao Centro se intensifica e a cidade vai ganhando seus contornos atuais: as classes de menor renda passam a ocupar os subúrbios, utilizando os trens urbanos como principal meio de transporte, e as classes mais abastadas dirigem-se aos novos bairros que vão sendo abertos no traçado dos transvias.

Assim, concordando com Elisabeth Weid, é inegável o papel dos bondes na expansão urbana das cidades de São Paulo e Rio de Janeiro. Por isso, acreditamos que ainda há muito a se estudar sobre a influência e as estratégias das empresas na implantação desses serviços, pois, além dos altos rendimentos capitalistas que a Light São Paulo e a Light Rio de Janeiro obtiveram, vimos também, nesse processo, a significativa expansão do tecido urbano nessas duas grandes metrópoles.

\section{A formação do patrimônio territorial da Light and Power no Rio de Janeiro: a produção do Complexo de Ribeirão das Lajes}

A concessão para produção e distribuição de energia gerada por hidrelétrica no estado do Rio de Janeiro foi adquirida pelo engenheiro britânico William Reid em dezembro de 1899. Com essa aquisição, Reid iniciou, em 1903, a construção do reservatório de Ribeirão das Lajes, distante $80 \mathrm{~km}$ da cidade do Rio de Janeiro, na área do planalto do Médio Vale do Paraíba. Essa concessão foi vendida à Light em dezembro de 1904, quando então se retomaram as obras, e a nova Companhia concluiu a construção da represa e da usina de Fontes, em 1908, iniciando efetivamente a geração de energia hidrelétrica de grande porte no estado.

Diversos foram os impactos causados pela construção dessa represa na região sul fluminense, inclusive a extinção de um município, São João Marcos ${ }^{1}$. Município onde nasceu o ex-prefeito da cidade do Rio de Janeiro, engenheiro Pereira Passos, a cidade de São João Marcos chegou a ser uma das mais populosa do estado, contando com cerca de 20 mil habitantes até o início do século XX. A Light recebeu o direito a desapropriação das terras em 1941, quando o Presidente Vargas, no início do Estado Novo, concedeu o destombamento da cidade, que tivera suas construções tombadas pelo antigo SPHAN como Patrimônio Histórico da Humanidade dois anos antes.

Esse fato expressa o intenso movimento de expansão do sistema de armazenamento de água nas represas, geração de energia e, consequentemente, formação de um imenso latifúndio, de propriedade da empresa até os dias de hoje. Um ano antes da conclusão das obras, em 19 de abril de 1907, o governo do estado do Rio de Janeiro deu autorização para que fosse aumentada a disponibilidade hídrica do Reservatório de Lajes por meio de um desvio parcial das águas do rio Piraí, afluente do Paraíba do Sul. A potência econômica que proporcionaria o desvio dessas águas para o Ribeirão das Lajes era de tamanha importância que a companhia, a título de indenização, pagou aos cofres do Estado a 
quantia de mil contos de réis, sendo 500 em dinheiro e 500 em apólices do empréstimo popular realizado pelo Estado do Rio de Janeiro. Vale ressaltar que os municípios de São João Marcos, Rio Claro e Piraí não receberam compensação alguma do governo nessa indenização (Dantas, 1938).

A intenção da empresa de se expandir era evidente e, à medida que a energia elétrica se tornava cada vez mais parte integrante do cotidiano da cidade, a necessidade de aumentar a produção também crescia. Complementarmente a isso, a Light já pensava em estratégias que promovessem a instalação de novas usinas e, por conseguinte, a sua consolidação na geração de energia no sul do estado do Rio de Janeiro.

Contudo, foi a partir do Governo Vargas, em face do aumento expressivo da demanda de energia elétrica e da necessidade de uma fonte adicional de água na cidade do Rio de Janeiro, que o governo autoriza a ampliação sem restrições do complexo de Ribeirão das Lajes. Em 1940, no governo do Presidente Getúlio Vargas, assinou o Decreto-Lei 2059/40, que previa o aumento da capacidade do reservatório de Ribeirão das Lajes - através da elevação de sua barragem - com o duplo intuito de suprir aumento da capacidade de geração de energia e, ao mesmo tempo, fornecer água à cidade. Tais objetivos são alcançados com a construção da segunda usina geradora de energia, a Usina de Fontes Nova (foto 2), e da adutora que corta todo o território entre a represa e a zona sul da cidade do Rio de Janeiro ${ }^{2}$. Esse sistema de abastecimento de água funciona até os dias de hoje.

No caso do Complexo de Lajes, após a construção da Usina de Fontes Nova o Grupo Light continuou se empenhando na elaboração de projetos para novas usinas. Em termos gráficos, visualizaremos, por meio das figuras que apresentaremos a seguir, representações dos sistemas de produção de energia e abastecimento de água criados do início do século XX até o início da segunda metade do século.

o primeiro subsistema desenvolvido pela empresa canadense é o sistema de Lajes, que se situa entre os municípios de Rio Claro e Piraí. Composto pelo Reservatório de Lajes, Reservatório de Tocos, Barragem de Tocos e pelas Usinas de Fontes Velha e Fontes Nova, tal subsistema é o responsável pela desocupação do município de São João Marcos, já mencionado. 
Figura 1. Ilustração do esquema de aproveitamento hídrico do Subsistema Lajes

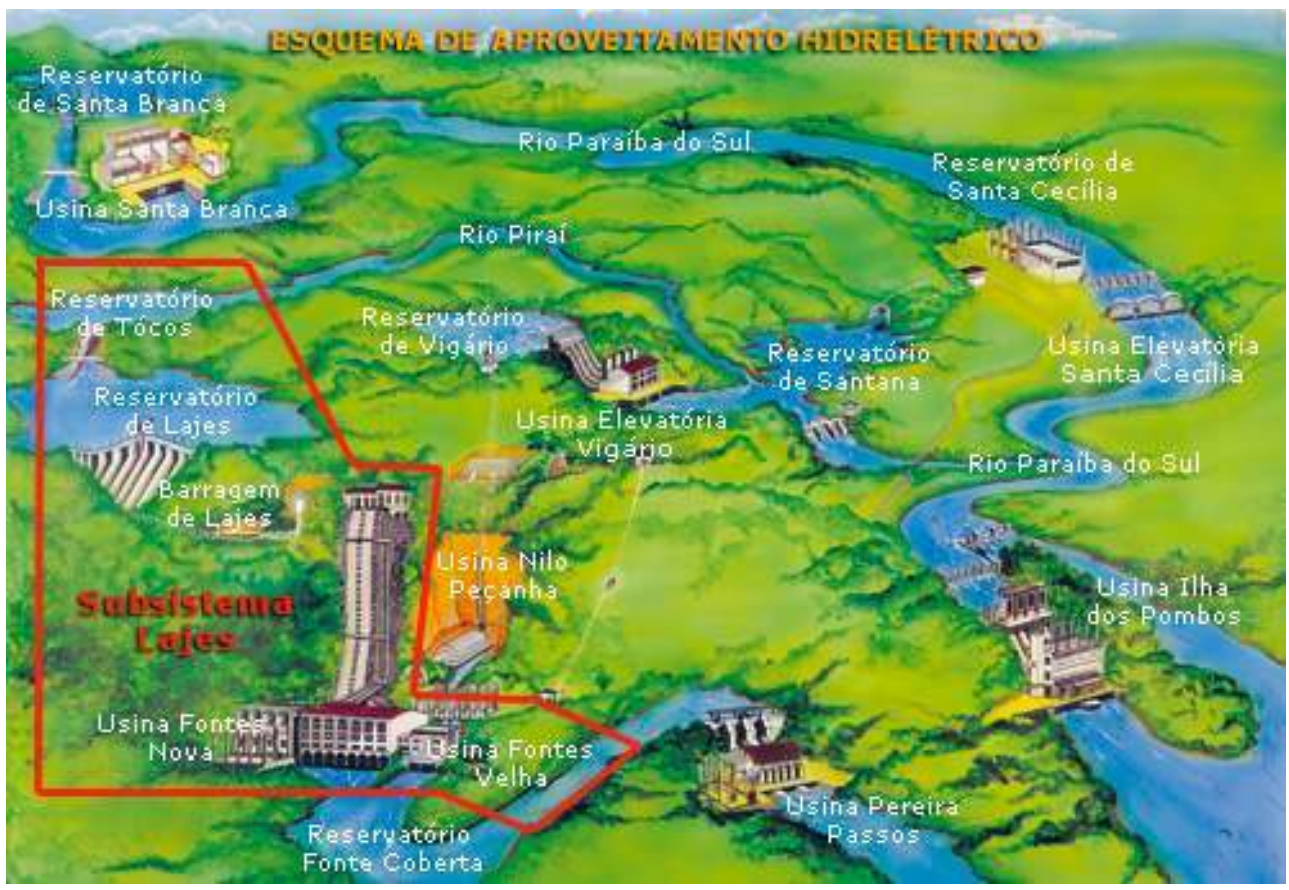

Fonte: Site Light e Energia.

Esse subsistema opera sob o conceito clássico de represa e usina associada, ou seja, o reservatório é interligado diretamente por dutos ao sistema de geradores da usina. Já o segundo sistema é mais complexo, pois opera com a transposição de águas do Rio Paraíba do Sul para a movimentação das turbinas nas novas usinas criadas nessa fase de expansão do sistema. Para a continuidade da ampliação de suas instalações, a Light foi autorizada pelo Governo Federal, em 1945, a desviar as águas do Rio Paraíba do Sul e do Rio Piraí para implantação de novas usinas hidrelétricas - Nilo Peçanha e Pereira Passos - que foram instaladas no entorno das usinas de Fontes Velha e Fontes Nova.

o funcionamento desse sistema começa com o fechamento do canal por onde o Piraí desaguava no Rio Paraíba do Sul. Com isso se institui o represamento do Rio Piraí e, por meio da transposição de águas do Paraíba do Sul, uma ampliação do seu volume de águas para a "nova" represa que surgia com o fechamento do canal. Essa "nova" represa, então, passa a receber contribuições de águas tanto das nascentes do Rio Piraí, no município de Rio Claro, localizado na Serra do Mar, quanto da transposição das águas do Paraíba do Sul. As águas dessa nova represa são bombeadas pela Estação Elevatória de Vigário, no centro da Cidade de Piraí, para os lagos artificiais que levam as águas dessa represa ao ponto de adutoração da Usina Nilo Peçanha, construída junto das usinas Fontes e Fontes Nova. 


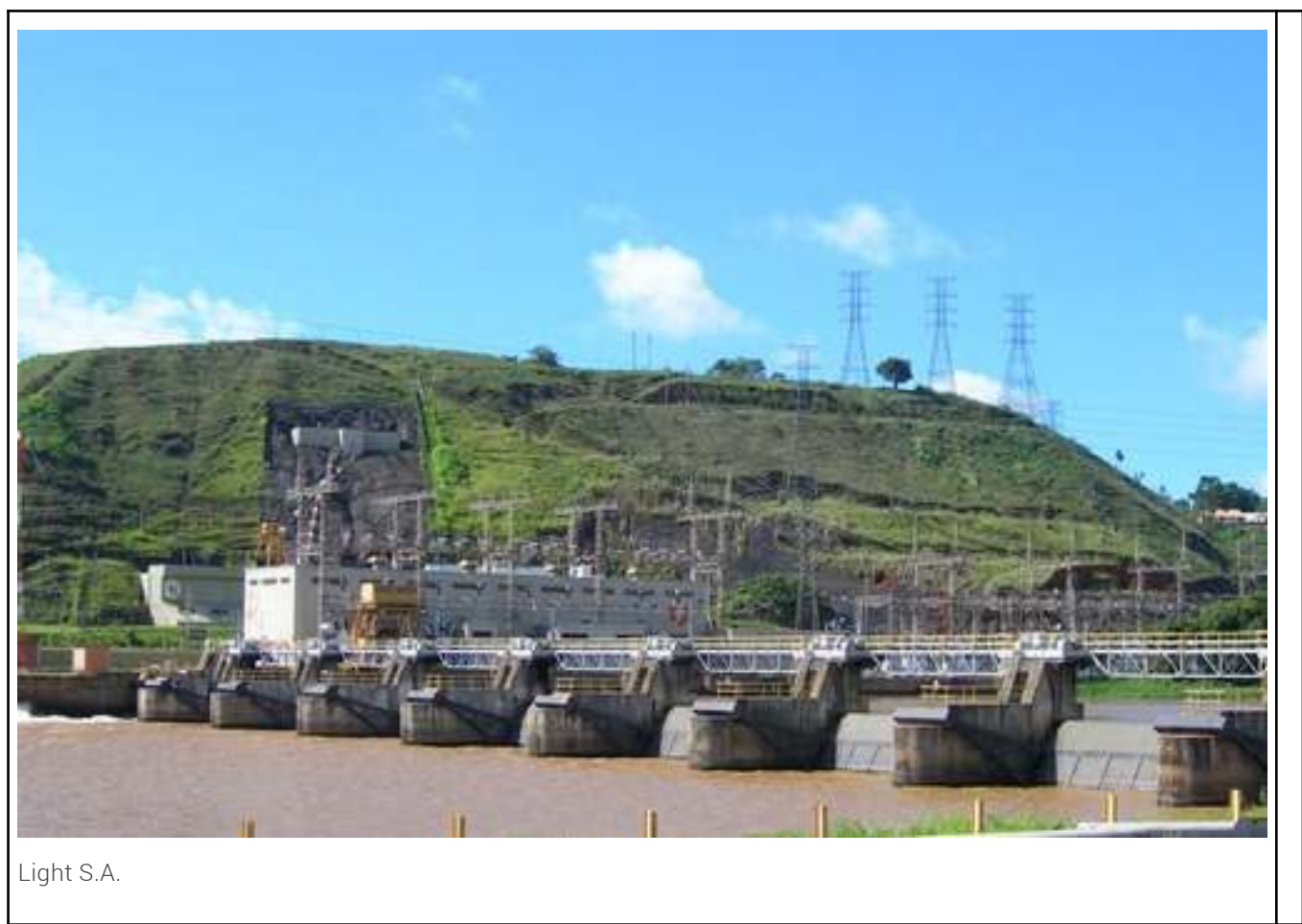

Foto 6. Estação Elevatória de Vigário, em Piraí.

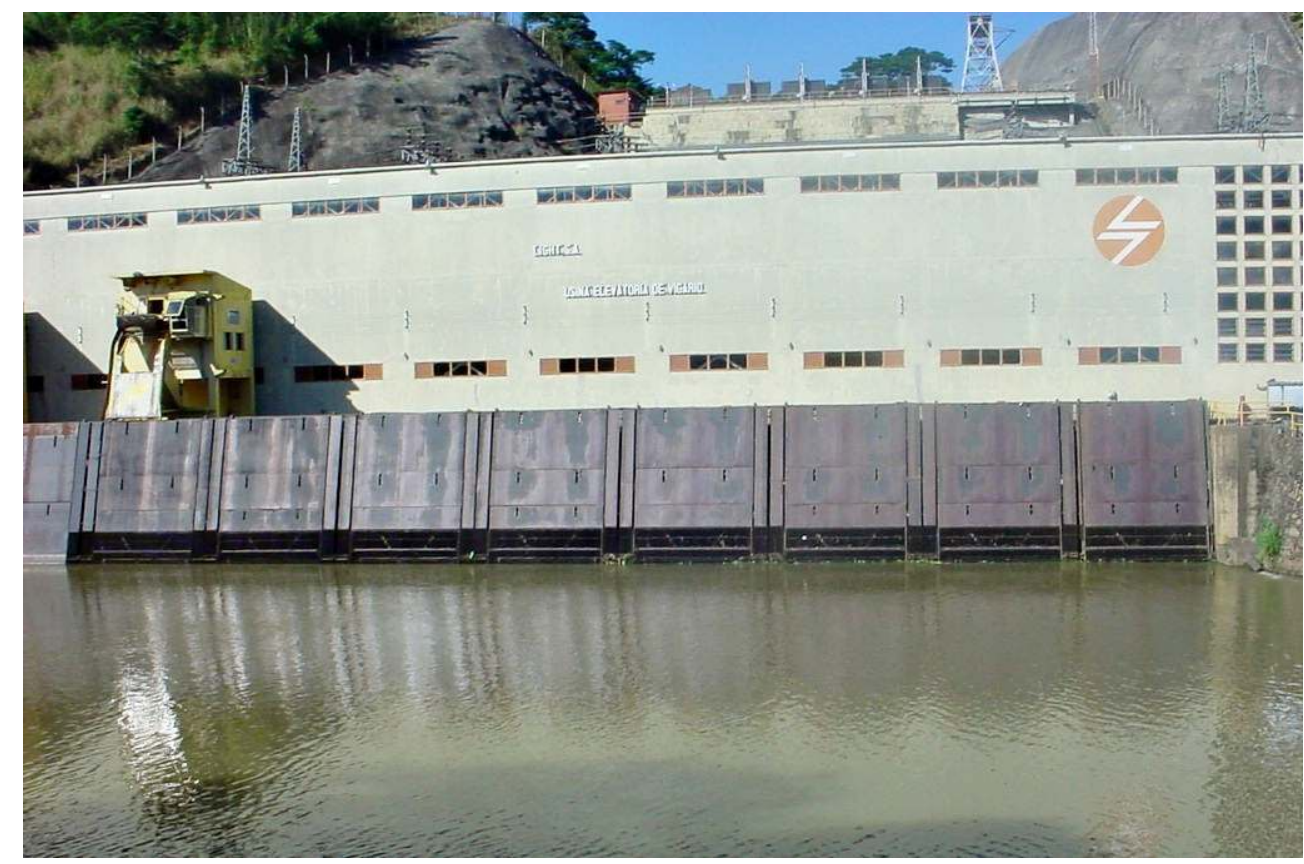

Floriano de Oliveira, 2005

Surge, então, o segundo subsistema daquele que viria a ser denominado Complexo de Lajes, o subsistema Paraíba-Piraí, conforme se pode observar a seguir. 
Figura 2. Ilustração do esquema de aproveitamento hídrico do Subsistema Paraíba-Piraí

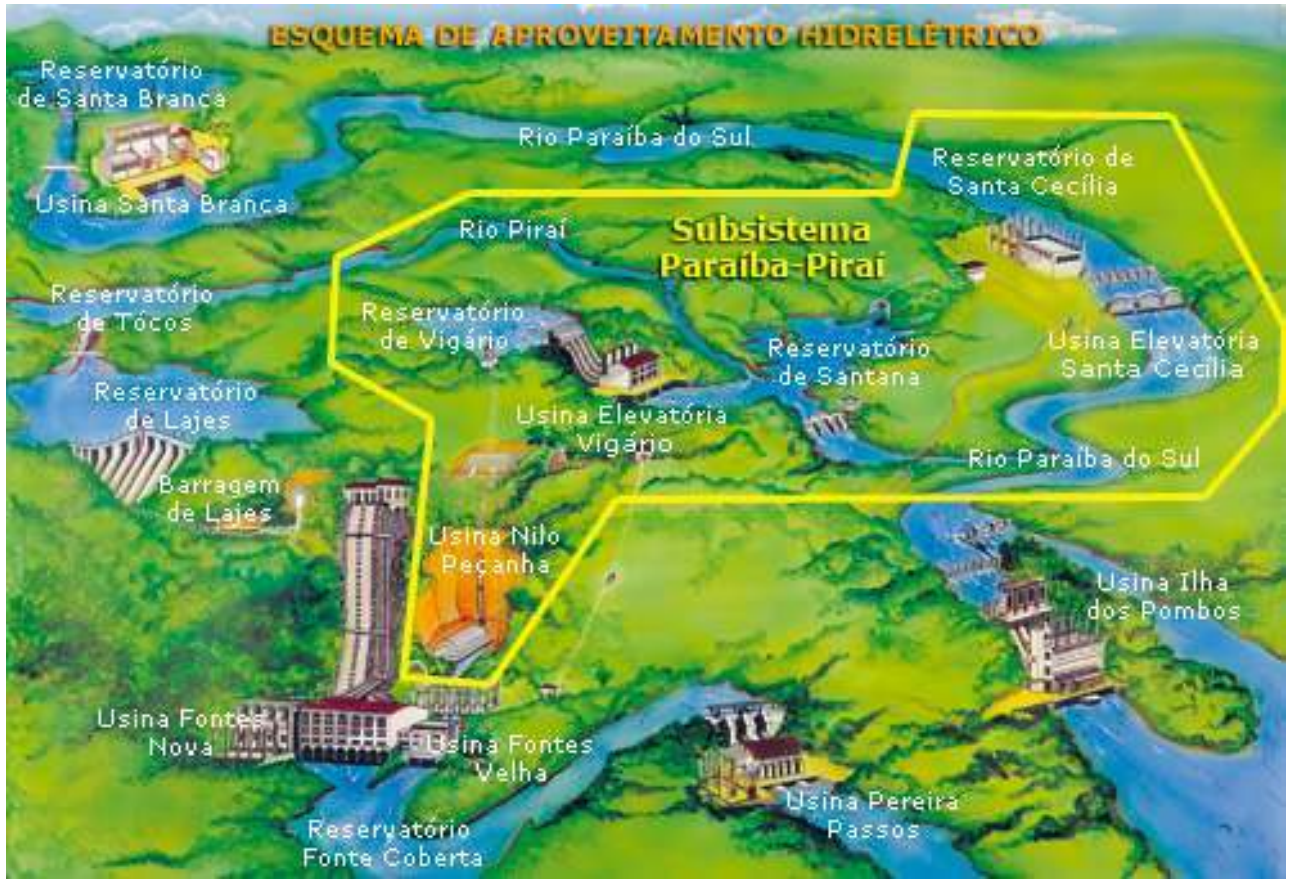

Fonte: Site Light e Energia.

Por fim, como aproveitamento final das águas usadas nos dois subsistemas, há ainda uma última utilização dessas águas pela Usina Pereira Passos. Trata-se de uma usina de menor capacidade, que aproveita a declividade natural do rio que se forma a jusante dos sistemas mais antigos, para geração de mais energia.

Figura 3. Ilustração do esquema de aproveitamento hídrico do Subsistema Pereira Passos

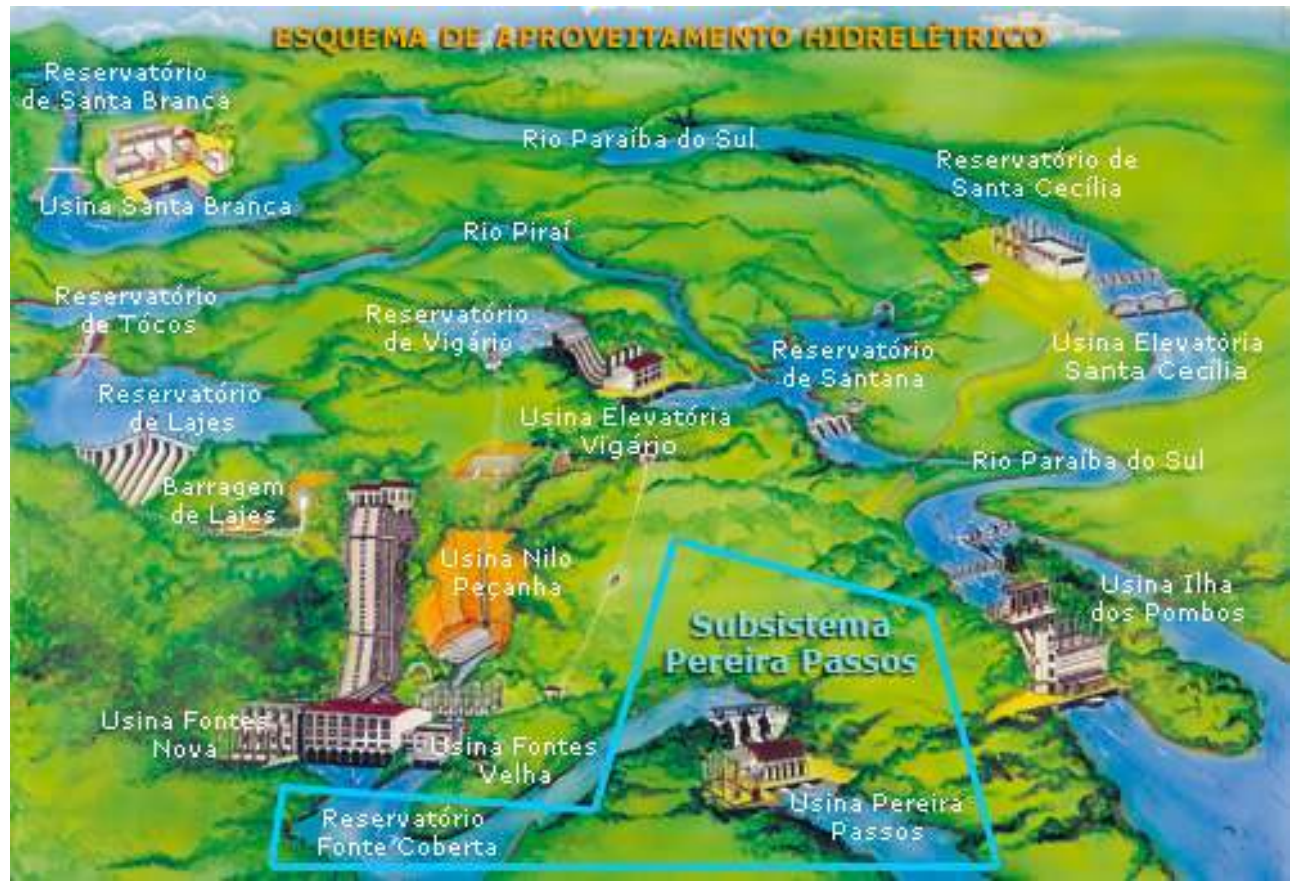

Fonte: Site Light e Energia. 
Ao avaliar a formação desses subsistemas verificamos que a constituição da Companhia, em seus 108 anos no estado, envolveu uma extensa área territorial, que ainda hoje compõe o patrimônio da Companhia. Seguramente podemos afirmar que tal propriedade constitui a maior propriedade fundiária do estado, que envolve parte dos territórios dos municípios de Piraí, Barra do Piraí, Rio Claro e Mangaratiba.

\section{A formação do patrimônio urbano: a expansão do tecido urbano seguindo os trilhos da Light}

37 A vinda da Light and Power para o Rio de Janeiro, após a compra dos direitos de geração de energia, em 1904, dependia também, para ser um empreendimento rentável, de autorização para atuação em outros ramos de prestação de serviços, em particular, a quebra da concessão de distribuição e iluminação pública concedida à Cia. Belga Société Anonyme Du Gaz. Tal questão envolveu uma acirrada disputa empresarial entre a Light e um dos principais grupos econômicos cariocas, o grupo Garffée \& Guinle, que também tinha interesses no ramo de serviços urbanos, e as demais pequenas empresas concessionárias.

O resultado dessa disputa e desse jogo de influências políticas foi a projeção do grupo The Rio de Janeiro Tramway Light and Power não para um setor específico de interesse da companhia, que era a produção e distribuição de energia, sobretudo para áreas de iluminação pública, mas, agora, estrategicamente, também para os serviços de transporte sobre trilhos e de distribuição de gás. A estratégia foi comprar as pequenas companhias de bondes e eletrificar o sistema a partir de pequenas usinas termoelétricas, e assim ir adquirindo forças para conseguir o monopólio.

39 Assim, a Light and Power, além dos investimentos para garantir as obras de construção da Represa de Ribeirão das Lajes e a Usina Hidrelétrica de Fontes, passou a adquirir as concessões e companhias preexistentes, como a Companhia Ferro-Carril de Vila Isabel, a companhia de telefones, a companhia de gás, em geral realizando parte do pagamento com a troca de títulos das companhias por títulos da Rio-Light (Weid, 2003). A estratégia logrou êxito após a entrada em operação da Usina de Fontes, em 1908, quando então, com base na alta disponibilidade de energia elétrica, a Companhia passa a se capitalizar e superar as inúmeras dificuldades na compra das demais concessionárias. A partir daquele ano a Light passa a exercer total domínio sobre os serviços no Distrito Federal, e as poucas empresas que ainda não pertenciam à Light foram sendo subjugadas e anexadas, através de compra direta ou controle acionário. Assim foi com a empresa Braconnot \& Irmãos, produtora de energia elétrica por meio de termoelétrica; a empresa inglesa Companhia Ferro-Carril, proprietária do Hotel Corcovado; a Cia. Ferro Carril de Jacarepaguá, com 15 $\mathrm{km}$ de trilhos, adquirida em 19117; várias empresas nacionais de bondes, como a Companhia de São Cristóvão, a Companhia de Carris Urbanos e, sobretudo, a Companhia de Ferro Carril do Jardim Botânico. Esta última teve sua anexação definitiva em 1910.

O transporte de massas ferroviário e as companhias de carris (bondes) foram dois elementos fundamentais para a expansão da cidade do Rio de Janeiro e passaram a atuar emconjunto. Isso porque o transporte de massas (trens) permitiu o desafogo do Centro e as companhias de carris ampliaram a malha urbana muito além do antigo Centro e até mesmo da Cidade Nova, que se formava na época. A maneira como se deu esse processo 
levou a uma nova estruturação social do espaço, principalmente devido à importância dos bondes na organização e na ampliação da malha urbana do Rio de Janeiro.

Até o início do século XX, portanto a Cia. de Carris Jardim Botânico, bem como inúmeras outras companhias menores que se formaram ao longo dos anos, foram elementos fundamentais na expansão e urbanização dos principais bairros e vias de acessos hoje existentes na cidade do Rio de Janeiro. Essa expansão, promovida em um primeiro momento pelos bondes de tração animal, foi posteriormente intensificada com o início dos processos de eletrificação dos mesmos com a chegada da Light and Power à cidade do Rio de Janeiro.

Com efeito, a partir de 1907 a Light and Power entra no ramo de transportes sobre trilhos e intensifica a ocupação e expansão urbanas apoiada na eletrificação dos bondes. Tal fato tanto potencializa as linhas e a ocupação da zona sul da cidade como oferece maiores possibilidades de expansão da zona norte em trechos mais afastados da rede ferroviária, adensando a região conhecida como Tijuca, Andaraí e Engenho Novo. 0 Mapa 1, mostrado a seguir, também publicado por Elizabeth Weid (2003), mostra a intricada rede de linhas de bondes que atuavam como complemento à rede ferroviária.

Mapa 1 : Rede de linha de bondes (1907)

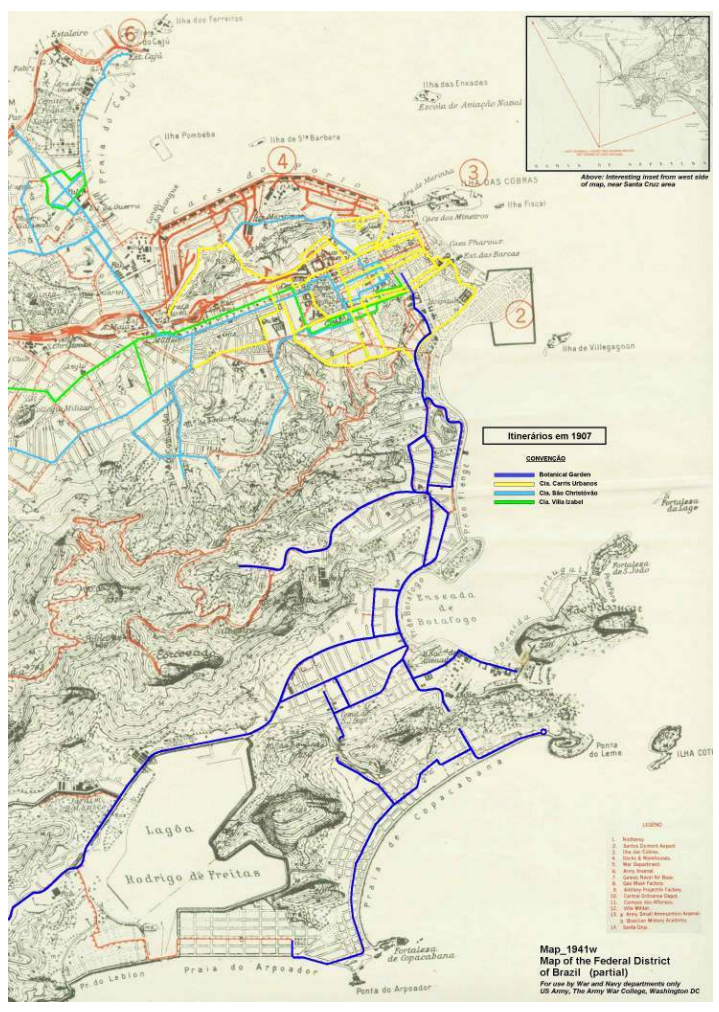

Fonte: http://www.bondesrio.com/paginas/basicas/frame_home_novo.html

Entre 1905 e 1907, enquanto construía a represa e a usina de Lajes, a Light atuou no sistema de bondes adquirindo as empresas ou assumindo seu controle acionário. Assim, em 1907, consegue um contrato de unificação das três maiores empresas que operavam a partir do centro da cidade em direção à zona norte e aos subúrbios: a São Cristóvão, a Vila Isabel e a Carris Urbanos. Tendo o domínio dessas empresas, a Light passa a investir intensamente na aquisição e expansão de sua rede para todo o subúrbio carioca, estabelecendo uma grande rede de transportes complementares às ferrovias. 

comando o maior número possível de concessionárias de serviço de utilidade pública. Elaborou, então, uma intricada articulação técnica e política de modo a conseguir apoio nas esferas governamentais para, ao mesmo tempo, garantir a concessão monopolista de alguns serviços, para afastar a concorrência, e ampliar ao máximo possível os prazos das concessões. Com isso, tornou-se, em poucos anos, a maior e praticamente única empresa concessionária de serviços de utilidade pública na cidade do Rio de Janeiro.

A empresa, a partir da produção e de uma ampla rede de distribuição de energia, destacou-se em dois campos estratégicos da expansão urbana da cidade: a modernização do parque industrial, oferecendo energia elétrica em quantidade suficiente para ampliação das operações industriais; e a eletrificação de todo o sistema de bondes, permitindo um alcance espacial infinitamente superior às possibilidades oferecidas pelo antigo sistema de tração animal.

49 Nesse último campo é relevante acrescentar que, quando a Light chegou ao Rio, já havia implantada uma importante rede de transportes, mas baseada em pequenas empresas isoladas. A unificação de todo o sistema foi o marco de um modelo de concentração e dominação dos serviços, cujo resultado é a instituição de um modelo de oferta privada de serviços de utilidade pública que até hoje marca a constituição da estrutura de oferta e 
exploração desses serviços, e que compromete totalmente a qualidade e a quantidade de seu fornecimento.

\section{BIBLIOGRAFIA}

ABREU, M. de A. A evolução urbana do Rio de Janeiro. $2^{\mathrm{a}}$. ed. Rio de Janeiro: IPLANRIO/Zahar Editores, 1988.

ANDREATTA, V. Ciudades cuadradas, paraísos circulares: planes de ordenación y orígenes de la urbanística en Rio de Janeiro (importación y transformación de paradigmas). Barcelona, Tesis douctoral, Universitat oberta, 2007.

BERENGUER G. A. Els territoris del negoci elèctric: el model de Pearson i la seva aplicació a Sao Paulo, México D.F., Rio de Janeiro i Barcelona. Barcelona, Tesis, Universitat Politècina de Cataluña. Departamento d'Infraestructura del transporti del territotori. 2008. <http:// hdl.handle.net/2099.1/5773>

CABRAL, L. M. Light: um século de muita energia (1905-2005). Rio de Janeiro: Centro da Memória da Eletricidade no Brasil, 2005. 144 p.

ETP -ESCELSA. Espírito Santo Centrais Elétricas SA. Site http://www.escelsa.com.br/energia/ pesquisadores_estudantes/energia_eletrica/historia_energia_eletrica/ historia_energia_eletrica.asp>

FREIRE, A. G. A guerra de posições na metrópole. Rio de Janeiro: Editora FGV, 2011.

FERREIRA, M. M. A evolução da iluminação na Cidade do Rio de Janeiro: contribuições tecnológicas. Rio de Janeiro: Synergia-Light, 2009.

HARVEY, D. A justiça social e a cidade. São Paulo: Editora Hucitec, 1980.

LEFEBVRE, H. O direito à cidade. São Paulo: Ed. Moraes, 1991.

LESSA, C. O Rio de todos os Brasis. (Coleção Metrópoles.). Rio de janeiro: Editora Record, 2000.

LLOYD'S Greater Britain Publishing Company, Ltd. Impressões do Brazil no século vinte, 1913. Disponível em http://www.novomilenio.inf.br/santos/h0300g38c.htm.

MCDOWALL, D. Light: a história da empresa que modernizou o Brasil. Rio de Janeiro: Ediouro, 2008.

MOTTA, M. Rio, cidade-capital. (Coleção Descobrindo o Brasil.) Rio de Janeiro: Jorge Zahar Editores, 2004.

OLIVEIRA, F. J. G. de. Redes técnicas e urbanização: a influência da Light and Power no desenvolvimento urbano e industrial do Rio de Janeiro. Simposio Internacional: Globalización, innovación y construcción de redes técnicas urbanas en América y Europa, 1890-1930. Brazilian Traction, Barcelona Traction y otros conglomerados financieros y técnicos. Barcelona, Espanha, Universidad de Barcelona, Janeiro de 2012.

SERQUEIRA, C. M. Mapas antigos. Disponível em: <http://www.serqueira.com.br/mapas/ lages7.htm> Acesso em: 25/8/2011. 
TEIXEIRA, L. G. S. História breve do bairro de Botafogo. Rio de Janeiro: Casa de Ruy Barbosa. http:// www.casaruibarbosa.gov.br/interna.php?ID_S=191

VAZ, V. J. B. As estratégias de ocupação da Light no Sul do estado do Rio de Janeiro. Trabalho de conclusão de curso (graduação em Geografia). São Gonçalo, RJ, UERJ : Faperj, 2012.

. A Represa de Ribeirão das Lages e os efeitos socio-espaciais no planalto da Serra do Mar no sul do Estado do Rio de Janeiro. Simpósio Internacional: globalización, innovación y construcción de redes técnicas urbanas en América y Europa, 1890-1930 - Brazilian Traction, Barcelona Traction y otros conglomerados financieros y técnicos. Barcelona, Espanha, Universidad de Barcelona, Janeiro de 2012.

WEID, E. Von der. A interferência da eletrificação sobre a cidade: Rio de Janeiro (1857-1914). Rio de Janeiro, Fundação Casa de Rui Barbosa, 2003. http://www.abphe.org.br/congresso2003/Textos/ Abphe_2003_35.pdf

WEID, E. Von der. A expansão da Rio de Janeiro Tramway Light and Power ou as origens do "Polvo Canadense". Rio de Janeiro, Fundação Casa de Rui Barbosa, 2003. http:// www.casaruibarbosa.gov.br/interna.php?ID_S=191

WEID, E. Von der. O bonde como elemento de expansão urbana no Rio de Janeiro. Rio de Janeiro, Fundação Casa de Rui Barbosa, 1994. http://www.casaruibarbosa.gov.br/interna.php?ID_S=191

\section{ANEXOS}

Sites

Bondes do Rio. Disponível em:

http://www.bondesrio.com/paginas/basicas/frame_home_novo.html Acesso em: $20 / 8 / 2011$.

Cronologia da instalação dos bondes na cidade do Rio de Janeiro.

http://usuarios.multimania.es/emidiogarde/eletricos/cronbondrj.htm

Centro da Cidade. Consultado em 5/9/2011.

http://www.centrodacidade.com.br/acontece/vs_pracaonze.htm

Condomínio Etc

http://www.condominioeetc.com.br/30/historia.shtml

Light S.A. Site.

http://www.light.com.br/web/institucional/projetos_geracao/teahelajes.asp\#central

\section{NOTAS}

1. Fundada em 1737, a cidade de São João Marcos localizava-se no reverso da Serra do Mar e pertencia ao perímetro correspondente ao Médio Vale do Paraíba, tendo seu auge no ciclo do café, como uma das rotas que se consolidaram através do escoamento da produção que ocorria pelo litoral no sentido Rio - São Paulo. 
2. A Usina de Fontes Velha recebeu a inclusão de duas adutoras na década de 1940. Construídas pelo governo federal, as denominadas "adutoras da CEDAE" foram instaladas para suprir as águas restituídas pelas turbinas da Usina, com o objetivo de abastecer de água o antigo Distrito Federal.

\section{RESUMOS}

Esse artigo apresenta alguns aspectos sócio-espaciais da formação do patrimônio fundiário e suas implicações na situação da Companhia de Eletrificação Light and Power Rio de Janeiro. Queremos destacar a ocupação de grandes quantidades de terras para controlar o sistema hídrico e a indução da urbanização da cidade. Esta última ocorre por meio de ações especulativas e do direcionamento dos vetores de crescimento vinculados à expansão do sistema de transportes na cidade do Rio de Janeiro. Analisamos também a ocupação de um amplo território na região sul do estado, que gerou o complexo de Furnas e, ao mesmo tempo, a estruturação de uma ampla rede de serviços públicos e de monopólio no setor de transportes urbanos. $O$ objetivo central de nossa pesquisa é mostrar a associação entre a estratégia empresarial e as articulações políticas que viabilizaram tal empreendimento.

Cet article aborde quelques aspects socio-spatiaux de la formation du patrimoine foncier et de son implication avec la Compagnie d'électrification Light and Power de Rio de Janeiro. Nous allons remarquer l'occupation d'une grande quantité de terres pour contrôler le système hydrique et pousser l'urbanisation de la ville. Cette dernière se vérifie au moyen d'actions spéculatives et du développement des directions de croissance urbaine liées à l'expansion du système des transports dans la ville de Rio. Nous analysons aussi l'occupation d'un vaste territoire dans la région du sud de l'État de Rio, qui a engendré le complexe de Furnas en même temps que la structuration d'un vaste réseau de services publics et du monopole des transports urbains. Le but principal de notre recherche est de montrer l'association entre la stratégie d'entreprise et les articulations politiques qui ont rendu possible cette réalisation.

This paper deals with the social spatial aspects of the formation of property patrimony and its implication in the Light and Power electrification company in Rio de Janeiro. We stress the occupation of a great amount of land to control the hydraulic system and to push the city's urbanization. The latter took place thanks to speculative actions and the direction of the city growth's axes according to the Rio's transportation system. We analyze also the occupation of a vast territory in the southern region of the Rio's state, which generated the complex of Furnas as well as the structuration of a wide network of public services, and the monopole of urban transportations. The main aim of our research is to show the association between the enterprise's strategies and the political articulation that made possible these realizations.

Este artículo presenta algunos aspectos socio-espaciales de la formación del patrimonio inmobiliario y sus implicaciones en la situación de la Compañía de Electrificación Light and Power Rio de Janeiro. Queremos destacar la ocupación de grandes cantidades de tierra para controlar el sistema hidrográfico y la inducción de la urbanización de la ciudad. Esta última ocurre por medio de acciones especulativas y del envío de señales de crecimiento vinculados a la expansión del sistema de transportes en la ciudad de Río de Janeiro. También analizamos la ocupación de un amplio territorio en la región sur del Estado, que dio origen al complejo de Furnas $\mathrm{y}$, al mismo tiempo, la estructuración de una amplia red de servicios públicos y de 
monopolio en el sector de transportes urbanos. El objetivo central de nuestra investigación es mostrar la asociación entre estrategia empresarial y las articulaciones políticas que dieron viabilidad a tal inversión.

\section{ÍNDICE}

Palavras-chave: eletrificação brasileira, Light, Rio de Janeiro, história econômica, geografia econômica

Palabras claves: electrificación brasilera, Light, Río de Janeiro, historia económica, geografía económica

Mots-clés: électrification brésilienne, Light, Rio de Janeiro, histoire économique, géographie économique

Keywords: Brazil electrification, Light, Rio de Janeiro, economic history, economic geography

\section{AUTOR}

\section{FLORIANO JOSÉ GODINHO DE OLIVEIRA}

Professor do Programa de Pós-Graduação em Políticas Públicas e Formação Humana (PPFH, Universidade do Estado do Rio de Janeiro. Email:fgodinho@uerj.br 